\title{
Pulpal Involvement-Roots-Sepsis Index: A New Method for Describing the Clinical Consequences of Untreated Dental Caries
}

\author{
Joanna Baginska Wanda Stokowska \\ Department of Restorative Dentistry, Medical University of Bialystok, Bialystok, Poland
}

\section{Key Words}

Caries $\cdot$ Epidemiology $\cdot$ PUFA/pufa $\cdot$ PRS/prs

\begin{abstract}
Objectives: To describe a modification of the index of clinical consequences of untreated dental caries [pulpal involvement, ulceration, fistula and abscess (PUFA/pufa) index] to pulpal involvement-roots-sepsis (PRS/prs) and to compare the two indices using the example of caries in primary molar teeth in children aged 6-8 years. Subjects and Methods: The study sample included 542 children aged $6-8$ years, from five randomly selected schools in the Bialystok District, Poland. The occurrence of clinical consequences of untreated caries in deciduous molars using the pufa and prs indices was evaluated. Data were analysed to express the prevalence, the experience and the distribution of particular pufa and prs codes in the sample population. The differences in layout of the pufa and prs components were expressed. Results: The response rate was $77.6 \%$. The prevalence of the clinical consequences of untreated caries was $40.77 \%$, mean pufa and prs were the same $(0.85 \pm 1.33)$. According to the pufa index, the following mean values were obtained: $p=0.79, u=0.01, f=$ 0.04 and $a=0.01$. For the prs index, the mean values were as follows: $p=0.45, r=0.35$ and $s=0.05$. Conclusion: The proposed prs index was a useful epidemiological instrument for
\end{abstract}

the evaluation of the clinical consequences of untreated caries in the surveyed population. The PRS instrument could be a good alternative to the PUFA index.

Copyright $\odot 2013$ S. Karger AG, Basel

\section{Introduction}

At the beginning of the 21st century, dental caries is still a serious problem, especially in low- and middle-income countries [1-3]. The reasons include a high consumption of cariogenic food, the negligence in daily oral health practices and irregular dental check-ups $[4,5]$. In developed countries, the severity of the disease was reduced over the last decades and the non-cavitated lesions are more prevalent than cavities [6-9]. However, even in economically developed regions, there are groups from a lower socio-economic background with a higher risk of severe caries $[5,9,10]$. The outcome of primary teeth treatment is poor all over the world $[11,12]$. The differences in the epidemiological situation between countries and regions resulted in the development of new tools for the assessment of caries severity. But among several dozen different kinds of criteria for caries detection, only few distinguish the pulpal involvement and dental sepsis [6, $13,14]$. The need for an epidemiological tool for the eval-

\begin{tabular}{ll}
\hline KARGER & $\begin{array}{l}\text { ○ 2013 S. Karger AG, Basel } \\
1011-7571 / 13 / 0226-0555 \$ 38.00 / 0 \quad \text { Karger }\end{array}$ \\
E-Mail karger@karger.com & $\begin{array}{l}\text { This is an Open Access article licensed under the terms of the } \\
\text { Creative Commons Attribution-NonCommercial 3.0 Un- } \\
\text { ported license (CC BY-NC) (www.karger.com/OA-license), } \\
\text { applicable to the online version of the article only. Distribu- } \\
\text { tion permitted for non-commercial purposes only. }\end{array}$
\end{tabular}

Joanna Baginska

Department of Restorative Dentistry, Medical University of Bialystok

ul. M. Sklodowskiej-Curie 24a

PL-15-276 Bialystok (Poland)

E-Mail jbaginska@wp.pl 
uation of advanced caries stages with pulp exposure or dental sepsis undoubtedly exists $[13,14,15]$. The lack of a proper measurement methodology resulted in very limited data in the literature. Some studies reported needs for pulp care and for extraction registered by WHO codes for treatment needs [16], but such data have not often been presented in the literature.

In 2010, an index of clinical consequences of untreated caries (PUFA) was introduced by Monse et al. [13]. The index was developed in a similar way to the decayed missed filled teeth (DMFT) system as a sum of teeth with four different diagnoses. $\mathrm{P} / \mathrm{p}$ means pulpal involvement and is recorded when the caries process is so advanced that the opening of the pulp chamber is visible or when the crown is destroyed and only roots are left. U/u is for an ulceration of soft tissues caused by sharp edges of a dislocated tooth with pulpal involvement. F/f is diagnosed when a pus-releasing sinus tract related to a tooth with pulpal involvement is present and $\mathrm{A} / \mathrm{a}$ means the presence of an abscess. For the purpose of the population studies, the prevalence and experience of PUFA can be evaluated.

However, the role of the indices used in the epidemiological studies is not only to describe the disease itself but also, or primarily, to depict the range of treatment needs in the population to the health planners and policy makers. As regards the presentation of treatment needs, the construction of the PUFA index is not sufficient. We have some doubts with regard to the description of code $\mathrm{P}$ in PUFA [13]. The inclusion of two different clinical situations in a single code, i.e. teeth with cariously exposed pulp and teeth considered for extraction in which the carious process results in an extensive destruction of the crown with remaining roots or their fragments, causes that it is difficult to assess the actual treatment needs. In the first case, an effective endodontic treatment is possible, which can considerably extend the time when the tooth remains in the oral cavity, thus prevent consequences caused by a premature loss of dentition. The roots of primary teeth should be definitely extracted to prevent odontogenic infections. As regards the roots of permanent teeth, in some cases they can be left in the oral cavity provided that an endodontic treatment and a prosthetic reconstruction have been performed. In less affluent societies, however, because of the financial barrier the root extraction is the treatment of choice $[1,3]$. The need of distinguishing the ulceration code appears to be ambiguous as well because, most frequently, these are teeth with an extensive crown destruction which should be considered for extraction. It cannot be ruled out, how- ever, that a tooth being the cause of soft tissue damage can be left in the oral cavity after smoothing sharp edges, an endodontic treatment and a reconstruction of lost tissues. Not insignificant is the fact that in most available research studies it was the most rarely diagnosed PUFA code [17, 18]. Frencken et al. [14] and de Souza et al. [19] raised the issue of reasonableness of separating the codes relating to dental sepsis - a fistula (F) and an abscess (A) - as they both were a manifestation of the same condition and might interchange into each other. An argument in favour of joining the above codes is also a small percentage of teeth with the said diagnoses presented in the research studies on PUFA/pufa [13, 14, 17, 18].

Having analysed the presented doubts, we have come to the conclusion that the index of clinical consequences of untreated caries would benefit from a slightly different selection of diagnoses so that individual codes not only determine the progression of the carious process but also refer to the treatment needs. Our idea was to develop an index based on assumptions similar to PUFA, but allowing an easier presentation of the treatment needs.

Hence, the aim of this paper was to develop a new index of clinical consequences of untreated caries to be named the pulpal involvement-roots-sepsis index (PRS).

\section{Subjects and Methods}

The study protocol was approved by the Bioethical Committee of the Medical University of Bialystok, Poland. The study was preceded by a calibration session comprising theoretical and practical sessions. The theoretical training was conducted on the basis of available literature concerning the PUFA/pufa index [13]. The practical part consisted of examining, twice at a week's interval, 10 children aged between 5 and 7 years with a poor dental condition. The calibration session for this study was short because the examiner (J.B.) had 10 years' experience in epidemiological studies and was previously involved in a survey evaluating teeth using the pufa index.

The survey was conducted in the Bialystok District, Poland. The minimum study sample was assessed to be 358 subjects based on the following assumptions: 13,000 of 6- to 8-year-old children living in this area, $40 \%$ of pufa prevalence, $95 \%$ of confidence interval and 5\% measuring error. 698 children from five randomly selected schools in the Bialystok District were invited to the study. The parents' or guardian's consents for the child's participation in the study were obtained. The exclusion criteria were lack of parents' approval, the child's absence at school on the day of examination and the child's negative attitude during examination. The study covered 542 children aged between 6 and 8 years, mean age $7.60 \pm 0.80$. A total number of 3,977 primary molar teeth were examined.

One examiner (J.B.) and one person (J.K.) recording the results were involved in the data collection. The oral examination was conducted in schools, in artificial light with the use of a dental mir- 
Table 1. Description of the PRS index

\begin{tabular}{llll}
\hline Characteristic & Code & Description & Treatment \\
\hline Pulpal involvement & $\mathrm{P} / \mathrm{p}$ & Caries process reached pulp chamber & Endodontic treatment \\
\hline Roots & $\mathrm{R} / \mathrm{r}$ & $\begin{array}{l}\text { Caries process destroyed tooth structures to } \\
\text { non-restorable stage }\end{array}$ & Extraction \\
\hline Sepsis & $\mathrm{S} / \mathrm{s}$ & $\begin{array}{l}\text { A pus-releasing sinus tract or a pus containing swelling } \\
\text { related to the tooth is present }\end{array}$ & $\begin{array}{l}\text { Endodontic/surgical treatment with an } \\
\text { antibiotic therapy (permanent dentition) } \\
\text { Extraction (primary dentition) }\end{array}$ \\
\hline
\end{tabular}

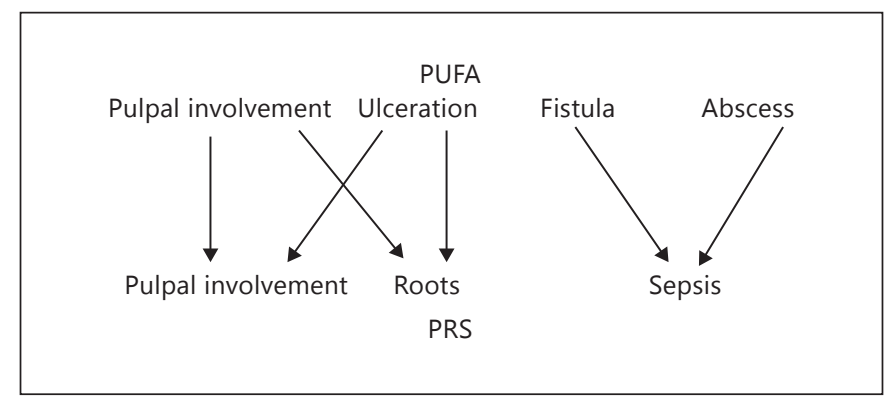

Fig. 1. The possible methods of transferring the diagnoses from PUFA to PRS.

ror. According to PUFA recommendations [13], no dental probe was used. All children were asked to brush their teeth before the oral examination. The presence of primary molars with cavities reaching the pulp chamber, injuries of soft tissues caused by teeth with severe caries and the presence of fistula or abscess were recorded. Also, teeth with extensive damage of hard tissues were recorded as roots in the assessment form.

Thus an instrument named PRS was developed. A description of the PRS is given in table 1 while the method of transferring the diagnoses from PUFA to PRS is presented in figure 1. Teeth diagnosed with a pulpal involvement $(\mathrm{P})$ according to PUFA were classified into the same category using the PRS index or were diagnosed as roots $(\mathrm{R})$. When using the PRS index, the examiner decided whether the tooth could be properly restored after endodontic treatment or not. Teeth with a bad prognosis for the direct or indirect restorative treatment were scored as roots. The same evaluation was carried out for teeth diagnosed as U (ulceration) in PUFA. The damage of soft tissues was done by sharp cavity edges or fragments of roots and such teeth were allocated to one of the PRS categories: pulpal involvement $(\mathrm{P})$ or roots $(\mathrm{R})$. Both manifestations of oral sepsis were classified separately in PUFA, scored as S component in PRS. Similar to DMF and PUFA, the PRS index was calculated for an individual as the sum of teeth with $\mathrm{P}$, $\mathrm{R}$ and $\mathrm{S}$ greater than 0 . The prevalence of PRS was counted as a percentage of the population with a PRS score of 1 or more. The mean PRS index was calculated as a quotient of the total sum of PRS values and the number of subjects in the sample group. For the primary dentition, the data were registered in lowercase letters

Pulpal Involvement-Roots-Sepsis Index as prs index. The minimum conditions for an oral cavity examination were artificial light and dental mirror; no probing of exposed pulp was done.

Data were analysed to express the prevalence, the experience and the distribution of particular pufa and prs codes in the sample population. The differences in the layout of the pufa and prs components were expressed. The intra-examiner reliability was determined using the unweighted kappa coefficient on a sample of $5 \%$ of the examined subjects.

\section{Results}

The response rate was $77.6 \%$. Of the 542 children, 221 (40.8\%) had untreated caries while of the 3,977 primary molar teeth, 461 (11.6\%) were diagnosed with severe caries. The unweighted kappa coefficient for pufa was estimated at 0.82 and for prs at 0.86 .

The mean values of both instruments were the same $(0.85 \pm 1.33)$. Differences were observed in the distribution of the components. With regard to pufa, pulpal involvement $(\mathrm{p})$ was diagnosed in $427(10.73 \%)$ teeth, and the mean $\mathrm{p}$ value was $0.79 \pm 1.27$. According to the prs index, this diagnosis was made in $244(6.13 \%)$ teeth with a mean of $0.45 \pm 0.89$. Other pufa codes were rarely diagnosed: a fistula (f) was observed in $24(0.6 \%)$ teeth, and soft tissue ulceration and an abscess in $5(0.13 \%)$ molars each. Taking into consideration the prs index, an extensive destruction of crown qualified as roots was found in $188(4.73 \%)$ teeth and a dental sepsis was diagnosed in 29 $(0.73 \%)$ molars. The mean values obtained by the pufa and prs indices are shown in table 2 while the clinical examples of PRS index categories are shown in figure 2.

The distribution of individual pufa codes with reference to the prs index is given in figure 3 . The group of teeth with pulpal involvement in the prs index consisted of 243 teeth with the diagnosis $p$ in pufa and of 1 tooth qualified as code $u$ in pufa. 184 teeth from the group of 

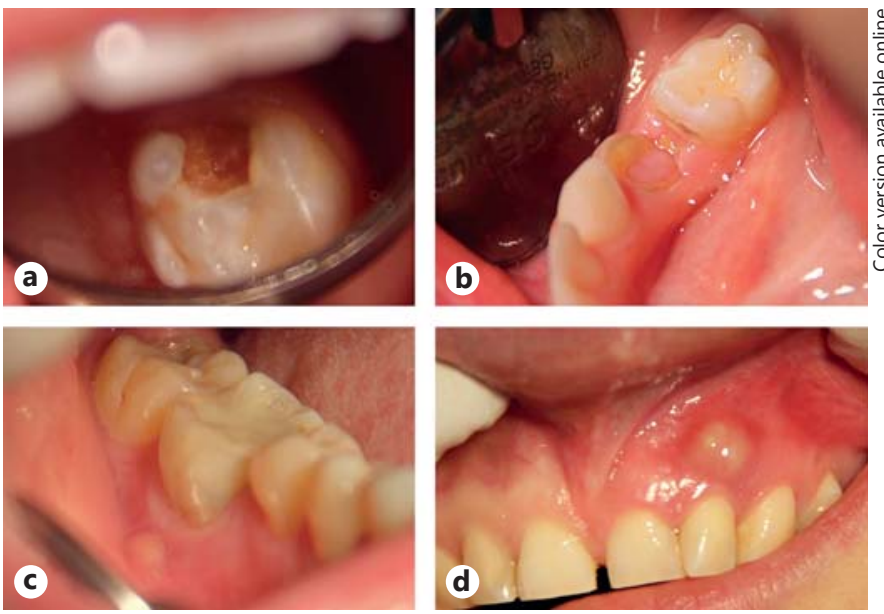

Fig. 2. The clinical examples of the PRS index categories. a Pulpal involvement $(\mathrm{P} / \mathrm{p})$. b Roots $(\mathrm{R} / \mathrm{r})$. c Fistula $(\mathrm{S} / \mathrm{s})$. d Abscess (A/a).

Table 2. Distribution of the number of teeth with clinical consequences of untreated dental caries and mean pufa and prs experience in surveyed population

\begin{tabular}{cccc}
\hline & $\begin{array}{l}\text { Total, } \mathrm{n}(\%) \\
(\mathrm{n}=3,977)\end{array}$ & Mean & SD \\
\hline pufa & & & \\
p & $427(10.73)$ & 0.79 & 1.27 \\
u & $5(0.13)$ & 0.01 & 0.09 \\
f & $24(0.6)$ & 0.04 & 0.27 \\
a & $5(0.13)$ & 0.01 & 0.09 \\
pufa & $461(11.59)$ & 0.85 & 1.33 \\
prs & & & \\
p & $244(6.13)$ & 0.45 & 0.89 \\
r & $188(4.73)$ & 0.35 & 0.78 \\
s & $29(0.73)$ & 0.05 & 0.28 \\
prs & $461(11.59)$ & 0.85 & 1.33 \\
\hline
\end{tabular}

pulpal involvement in pufa and 4 teeth classified as ulceration were assigned as roots ( $r$ ). The s component of the prs tool consisted of 24 teeth with fistula and 5 teeth causing abscess. No tooth with dental sepsis was qualified as dental roots.

\section{Discussion}

The population evaluated in the present study was characterised by a high prevalence $(40 \%)$ of advanced stages of dental caries expressed as the prs index. Most

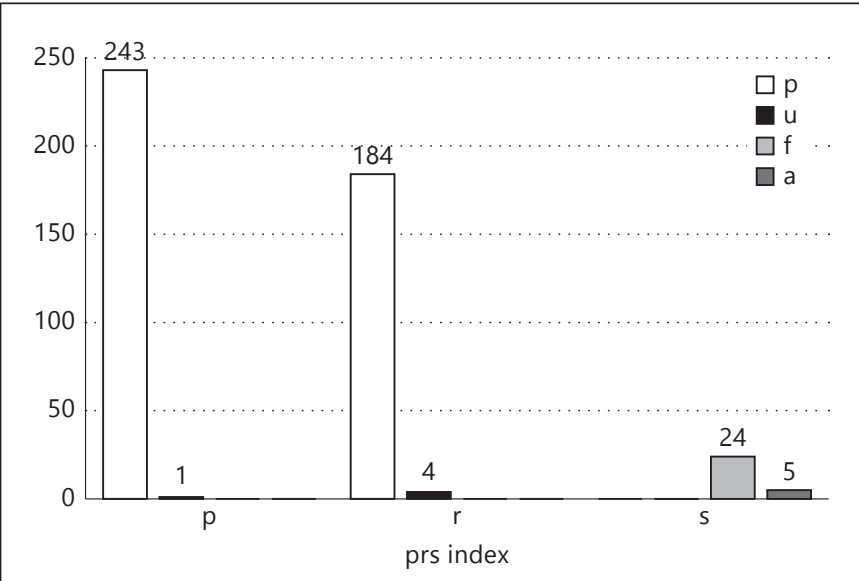

Fig. 3. The distribution of individual pufa codes with reference to the prs index in the surveyed population.

prevalent were teeth with pulpal involvement (6.13\%), while teeth causing dental sepsis $(0.73 \%)$ were rarely observed. The experience of prs was also high because it involved every tenth of the evaluated primary molars. Comparison of prs and pufa indices showed differences in the distribution of teeth with pulpal involvement. In fact, 184 molars diagnosed as pulpal involvement in pufa were classified as roots in prs and qualified for extraction. Only $0.13 \%$ of teeth caused the ulceration of oral mucosa, the code registered by pufa, but almost all of them were found to be roots.

The prevalence and experience of clinical consequences of caries obtained by prs compared with the pufa index were lower in Filipinos [13] but were higher in Brazilian children [18]. Children from the Philippines aged 6 years suffered from severe caries, with $84 \%$ of the population having teeth with positive pufa scores and the mean pufa at the level of 3.4 [13]. Six to 7-year-old children living in a deprived area of Brazil showed $23.7 \%$ of pufa prevalence and severity per child at 1.7. The pufa index in a previous study conducted in the same region of Poland was higher. It scored $2.20 \pm 3.43$ in 5-year-old children and $2.44 \pm 2.22$ in 7 -year-old children [17]. However, in view of the differences in age and type of evaluated teeth (posterior in our study vs. anterior and posterior in the previous one), an accurate comparison of obtained results was not possible. It should be emphasised that in all studies using the pufa index, most teeth with clinical consequences of untreated dental caries were classified as pulpal involvement. It is difficult to take up a wide discussion concerning the frequency of distribution of different codes be- 
cause no relevant reports, apart from the pufa index, were found in the literature. In a study on dental sepsis conducted in Scotland, the occurrence of fistula or abscess in $2-11 \%$ of examined 5 -year-old children was found whereas the frequency thereof increased with worsening socioeconomic status of the sample population [9].

Indices like PUFA or PRS are especially useful for the populations with neglected caries treatment and prevention. The PUFA index was at first used and validated in the national oral health survey in the Philippines $[13,20]$. From its introduction, it was applied in the studies on the epidemiology of caries and as a measurement tool in the research concerning the influence of dental caries on the general health and the quality of life $[17,18,21,22]$. The examination of oral cavity using the PUFA index was assessed as easy to conduct, with a good intra- and interexaminer reliability $[17,20,21]$. So the question might be asked whether there is a need for another instrument concerning the clinical consequences of untreated dental caries. The PUFA index is indeed a breakthrough tool for the estimation of the total number of dental conditions related to severe caries. However, in our opinion, it failed in the presentation of treatment needs of such teeth. Health care planners and policy makers should receive clear information about the full range of the disease spectrum, which means not only its prevalence and experience, but also the treatment needs. Determining a group of teeth considered for extraction due to crown destruction allows assessing possible consequences and costs of their loss. An early extraction of primary teeth can result in numerous consequences such as chewing and speech problems, and disturbances of eruption of permanent successors. Losses of teeth in the permanent dentition generate a cost-consuming prosthetic or implant treatment. The rationale for the modification of the index of clinical consequences of untreated caries was proven by the differences in the distribution of teeth between pufa and prs as observed in the present study. About $43 \%$ of teeth with the category pulpal involvement in pufa and almost all teeth diagnosed as ulceration were in fact so decayed that only their roots were left and they should be extracted.

In addition, it appears to us that the choice of codes in PUFA can be misleading for the recipients. The cumulative way of presenting different clinical conditions, i.e. teeth with a chance to remain in the oral cavity and roots, causes that PUFA gives a more positive picture of the dentition than it is in reality. In PUFA, the pulpal involvement component significantly exceeds other values. On the other hand, very small values of the other PUFA codes compared to the pulpal involvement, which may result in the marginalisation of such data, give rise to doubts. The proposed PRS index, based on the same data as PUFA, distributes it in a way which is clearer for medical practitioners, health policy makers and the general public.

It is noteworthy that the kappa values for both indices showed very good intra-examiner reliability, as in other studies $[17,18]$. In fact, both the pufa and the prs indices were based on the same data. The only differences were that the examiner had to decide whether or not the degree of crown destruction or the position of a tooth with severe caries qualified it for extraction and that there was no need to distinguish symptoms of dental sepsis. Further studies with a larger sample are planned in order to test the validity of PRS.

\section{Conclusions}

The evaluated population showed a high prevalence of severe caries. The prs index was a useful instrument for the evaluation of clinical consequences of untreated dental caries in the surveyed population and it provided additional information on dental status compared to the pufa index. The PRS instrument could be a good alternative to the PUFA index.

\section{Acknowledgement}

We would like to thank Ms Jadwiga Karpowicz for her assistance during data collection.

References

1 Ajayi YO, Sofola OO: Descriptors of permanent teeth with cariously exposed pulp in patients presenting at a Nigerian hospital. Acta Odontol Scand 2013, E-pub ahead of print.

2 Mobarak EH, Shabayek MM, Mulder J, et al: Caries experience of Egyptian adolescents: does the atraumatic restorative treatment approach offer a solution? Med Princ Pract 2011;20:545-549.

3 Jafarian M, Etebarian A: Reasons for extraction of permanent teeth in general dental practices in Teheran, Iran. Med Princ Pract 2013;22:239-244.

4 Ashkanank F, Al-Sane M: Knowledge, attitudes and practices of caregivers in relation to oral health of preschool children. Med Princ Pract 2013;22:167-172.

5 Akpata ES, Al Attar A, Sharma PN: Factors associated with severe caries among adults in Kuwait. Med Princ Pract 2009;18:93-99.

6 Ismail AI: Visual and visuo-tactile detection of dental caries. J Dent Res 2004;83(suppl): C56-C66. 
7 Kühnisch J, Berger S, Goddon I, et al: Occlusal caries detection in permanent molars according to WHO basic methods, ICDS II and laser fluorescence measurements. Community Dent Oral Epidemiol 2008;36:475-484.

8 Ismail A: Diagnostic levels in dental public health planning. Caries Res 2004;38:199203.

9 Pine CM, Harris RV, Burnside G, et al: An investigation of the relationship between untreated decayed teeth and dental sepsis in 5-year-old children. Br Dent J 2006;200:4547.

10 Edelstein BL: Disparities in oral health and access to care; findings of national surveys. Ambul Pediatr 2002;2(suppl 2):141-147.

11 Honkala E, Behbehani JM: What's new in the benefits of restoring primary teeth? Med Princ Pract 2013;22:207-208.

12 Tickle M, Milson K, Kong D, et al: The fate of the carious primary teeth of children who regularly attend the general dental service. $\mathrm{Br}$ Dent J 2002;192:219-223.
13 Monse B, Heinrich-Weltzien R, Benzian H, et al: PUFA - An index of clinical consequences of untreated dental caries. Community Dent Oral Epidemiol 2010;38:77-82.

14 Frencken JE, Amorim RG, Faber J, et al: The Caries Assessment Spectrum and Treatment (CAST) index: rational and development. Int Dent J 2011;61:117-123.

15 Fisher J, Glick M: A new model for caries classification and management. The FDI World Dental Federation Caries Matrix. J Am Dent Assoc 2012;143:546-551.

16 World Health Organization: Oral Health Surveys. Basic Methods, ed 4. Geneva, World Health Organization, 1997, pp 45-46.

17 Bagińska J, Rodakowska E, WilczyńskaBorawska $\mathrm{M}$, et al: Index of clinical consequences of untreated dental caries (pufa) in primary dentition of children from north-east Poland. Adv Med Sci 2013, E-pub ahead of print.
18 Figueiredo MJ, de Amorim RG, Leal SC, et al: Prevalence and severity of clinical consequences of untreated dentine carious lesions in children from a deprived area of Brazil. Caries Res 2011;45:435-442.

19 De Souza AL, van der Sanden WJM, Leal SC, et al: The Caries Assessment Spectrum and Treatment (CAST) index: face and content validation. Int Dent J 2012;62:270-276.

20 Benzian H, Monse B, Heinrich-Weltzien R, et al: Untreated severe dental decay: a neglected determinant of low Body Mass Index in 12-year-old Filipino children. BMC Public Health 2011;11:558.

21 Leal SC, Bronkhorst EM, Fan M, et al: Untreated cavitated dentin lesions: impact on children's quality of life. Caries Res 2012;46: 102-106.

22 Gradella CM, Bernabé E, Bönecker M, et al: Caries prevalence and severity, and quality of life in Brazilian 2- to 4-year-old children. Community Dent Oral Epidemiol 2011;39: 498-504. 